\title{
Trafficking in Human Beings. A Comparative Study of the International Legal Documents
}

Ana Isabel Pérez Cepeda; Demelsa Benito Sánchez.

\section{Reseña}

La Trata de Seres Humanos constituye uno de los problemas mundiales más alarmantes del siglo XXI que requiere una respuesta internacional completa y eficaz. En este contexto, la obra Trafficking in Human Beings. A Comparative Study of the International Legal Documents, desarrollada conjuntamente por la Catedrática Ana Isabel Pérez Cepeda y la Doctora Demelsa Benito Sánchez en el marco del proyecto de investigación FIDUCIA (FP7), supone una contribución académica esencial al estudio de la lucha internacional contemporánea contra la Trata de Seres Humanos.

En términos generales, la investigación tiene por objeto realizar un análisis comparado de los instrumentos jurídicos internacionales y europeos actuales más significativos en la materia, a saber: el Protocolo para prevenir, reprimir y sancionar la trata de personas, especialmente mujeres y niños, que complementa la Convención de las Naciones Unidas contra la Delincuencia Organizada Transnacional, hecho en Nueva York el 15 de noviembre de 2000; el Convenio número 197 del Consejo de Europa sobre la lucha contra la trata de seres humanos, hecho en Varsovia el 16 de mayo de 2005; y la Directiva 2011/36/UE del Parlamento Europeo y del Consejo, de 5 de abril de 2011, relativa a la prevención y lucha contra la trata de seres humanos y a la protección de las víctimas y por la que sustituye la Decisión Marco 2002/629/ JAI del Consejo.

Para lograr el fin propuesto, la obra se estructura muy acertadamente en cuatro apartados principales, a los que les sigue un Anexo complementario. 
Conforme a dicha estructura, el primer apartado recoge unas notas generales sobre el proyecto de investigación FIDUCIA en el que se enmarca la obra, un proyecto dedicado al análisis de "nuevos" delitos en el ámbito europeo desde la perspectiva de las políticas basadas en la confianza.

En el segundo apartado se realiza una aproximación clara y precisa a la Trata de Seres Humanos como presupuesto necesario para contextualizar la investigación. En concreto, las autoras presentan la Trata de Seres Humanos como un alarmante negocio criminal que está desarrollándose en todo el mundo y destacan que constituye una de las violaciones más dramáticas de los Derechos Humanos, especialmente, de la dignidad humana. A lo largo de este apartado, se describen las características básicas del fenómeno, se enumeran las principales causas que fomentan su expansión y se hace alusión a las cifras oficiales sobre su dimensión global.

El tercer apartado comprende un profundo análisis comparado de los tres instrumentos jurídicos mencionados. Primeramente, a modo de introducción, se realiza un recorrido por los instrumentos internacionales que han venido abordando la Trata de Seres Humanos desde la Declaración Universal de los Derechos Humanos, adoptada por la Asamblea General de las Naciones Unidas el 10 de diciembre de 1948, con el fin de mostrar la evolución normativa de las últimas décadas en la lucha contra este fenómeno. A continuación, las autoras llevan a cabo una comparación exhaustiva y detallada de los cinco ámbitos que abordan los instrumentos internacionales de referencia, esto es: la definición de la Trata de Seres Humanos; su penalización; su prevención; la protección de las víctimas; y la cooperación internacional en la lucha contra la misma. El estudio de cada uno de estos ámbitos comprende una explicación minuciosa sobre las similitudes y diferencias patentes entre los tres textos, así como una tabla en la que se resumen de manera esquemática los datos más significativos del análisis realizado. Sin duda alguna, este apartado constituye la principal aportación de la obra ya que existen pocos estudios similares que comparen de forma detallada las disposiciones de estos tres instrumentos.

En el cuarto apartado se recogen las conclusiones y los resultados obtenidos de la investigación. Concretamente, las autoras toman como referencia los cinco ámbitos estudiados en el apartado tercero y enumeran las conclusiones más significativas en relación con cada uno de ellos.

Junto con los cuatro apartados mencionados, la obra contiene un Anexo en el que se estudia la respuesta penal de cuatro países europeos (Finlandia, Grecia, España y Reino Unido) a la Trata de Seres Humanos. Este análisis permite conocer y valorar el alcance de las medidas adoptadas en las legislaciones internas para prevenir y combatir este fenómeno. Además, las autoras acompañan el estudio descriptivo de las disposiciones internas con valiosas recomendaciones a cada uno de los países para mejorar y perfeccionar la lucha actual contra la Trata de Seres Humanos. 
Con esto, es preciso destacar la claridad y el rigor con los que se aborda el objeto de la investigación, cualidades que evidencian su indiscutible calidad científica.

En suma, estamos ante una obra original y novedosa que constituye un trabajo indispensable para comprender la orientación actual de la lucha internacional contra la Trata de Seres Humanos.

Josune López Rodríguez 